\title{
FAB tandem mass spectra of aflatoxins, sterigmatocystin and their analogs $\dagger$
}

\author{
D. UYAKUL*1,2, M. ISOBE*1, , and T. GOTO*1
Duangehan UYAKUL ${ }^{* 1,2}$, 磯部 稔*1,8, 後藤俊夫*1: Aflatoxin sterigmatocystin 類
の FAB タンデムマススペクトル†

\begin{abstract}
Summary
The positive Fast Atom Bombardment (FAB) tandem mass spectrometry as an effective technique was applied for identification and confirmation of 20 mycotoxins such as aflatoxins $B_{1}$, $B_{2}, G_{1}$ and $G_{2}$, and sterigmatocystin and its related toxins. The fab $\mathrm{ms} / \mathrm{ms}$ technique demonstrated to be a good method for analyzing these mycotoxins with less than one microgram. It resolved complex mixture of mycotoxins even with the same molecular weight.
\end{abstract}

Mycotoxins produced by Aspergillus versicolor (Vuillemin) Tiraboshi, Emericella nidulans (Eidam) Vuill. and Bipolaris sp. are mainly sterigmatocystin, versicolorin and averufin. ${ }^{1,2}$ ) The above toxins were reported as biosynthetic precursors of aflatoxins. ${ }^{1)}$ The toxins are potential contaminants of foodstuffs and animal feeds. The health hazards associated with these toxins have posed serious problems for animals and humans spread out in the world. Natural contamination often occurs in trace amount. Accurate methods are required in determining the specific mycotoxins. For the analyses of mycotoxins, minicolumn, thin layer chromatography (TLC) and high performance liquid chromatography (HPL.C) become very useful techniques. Enzymelinked immunosorbent assay (ELISA) has been introduced for aflatoxin analyses ${ }^{3-6)}$. Recently, mass spectrometry (MS) proved to be an extremely valuable method to provide unambiguous identification of mycotoxins. Recent publications, using various techniques of mass spectrometry such as field desorption (FD) ${ }^{7}$, electron impact $(E I)^{8)}$ and negative ion chemical ionization (NICI) ${ }^{9}$, can be used in the identification of mycotoxins at a low level. However, it is necessary that samples must be extensively cleaned-up before analysis. In case of many mycotoxins or interferences having coincident molecular ion with other mycotoxin, the above techniques do not provide simultaneous specification of the mycotoxin. In this study, using positive Fast Atom Bombardment tandem mass spectrometry (FAB-MS/MS), we have demon.

$\dagger$ A paper presented during the 7th International Symposium on Mycotoxins and Phycotoxins, August 16-19, 1988 at Tokyo, Japan.

*1 Laboratory of Organic Chemistry, School of Agriculture, Nagoya University (Chikusa, Nagoya 464) 名古屋大学管学部生物有機化学研究室 (广464 名古屋市千種区不老町)

*2 A PhD candidate on study leave from Mycotoxin Laboratory, Division of Food Analysis, Department of Medical Sciences, Yodse, Bangkok, Thailand under the scholarship grant of the Ministry of Education, Science and Culture (Monbusho).

*2 To whom correspondence should be addressed. 
strated the identification of 20 mycotoxins including four pairs of mycotoxins with the same molecular weights.

\section{Materials and Methods}

\section{Chemical}

Aflatoxins were secured from Makor Chemicals LTD, Jerusalem, Israel. Sterigmatocystinrelated compounds were obtained from Prof. Hamasaki of Tottori University, Japan ${ }^{1)}$.

Mass Spectrometry

A JEOL JMS-DX 705L quadrupole doublet (QPD) mass spectrometer was used for FABMS/MS (tandem MS) analysis. It involves two JEOL JMS-DX300 instruments which are

Table 1. FAB-MS/MS of aflatoxins

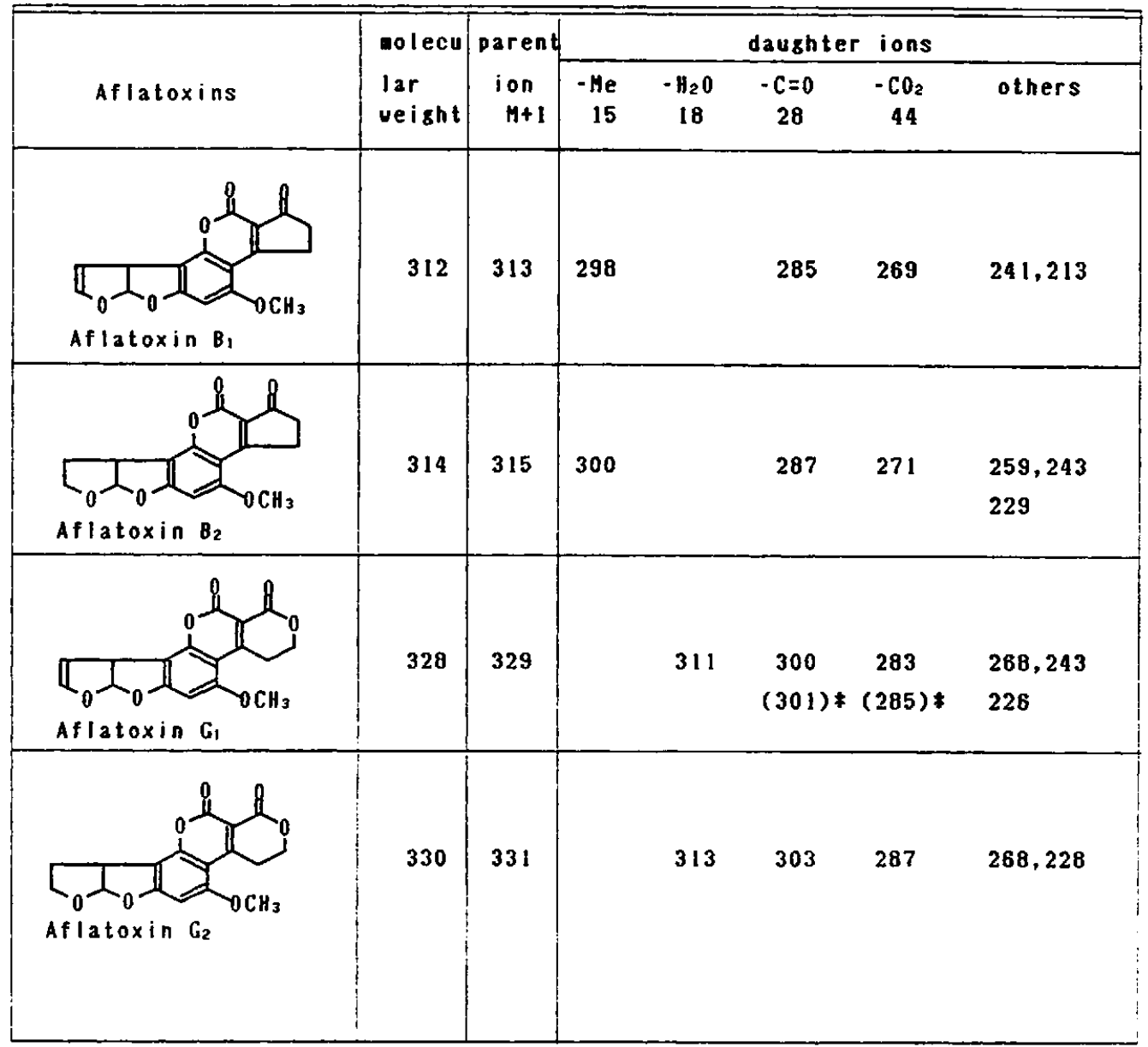

Condition of the FAB MS/MS : Instrument JEOL model DX705 L. 1st MS ionization positive $\mathrm{FAB} / \mathrm{Xe}$, acceleration $3 \mathrm{kV}$, matrix = glycerin +3-nitrobenzylalcohol, sample amount $<1 \mu \mathrm{g}$. 2nd MS collision with $\mathrm{He}$ at $10 \mathrm{mmHg}$.

Data process : average of accumulation 10 times.

* found in another measurement. 
combined together to become EB-EB through an interface with a He-collision chamber and a QPD to obtain daughter ions caused by the collisional activation. A mixture of glycerin and 3-nitrobenzylalcohol was employed as matrix in FAB measurements. Mycotoxin (less than

Table 2. FAB-MS/MS of sterigmatocystin and its analogs

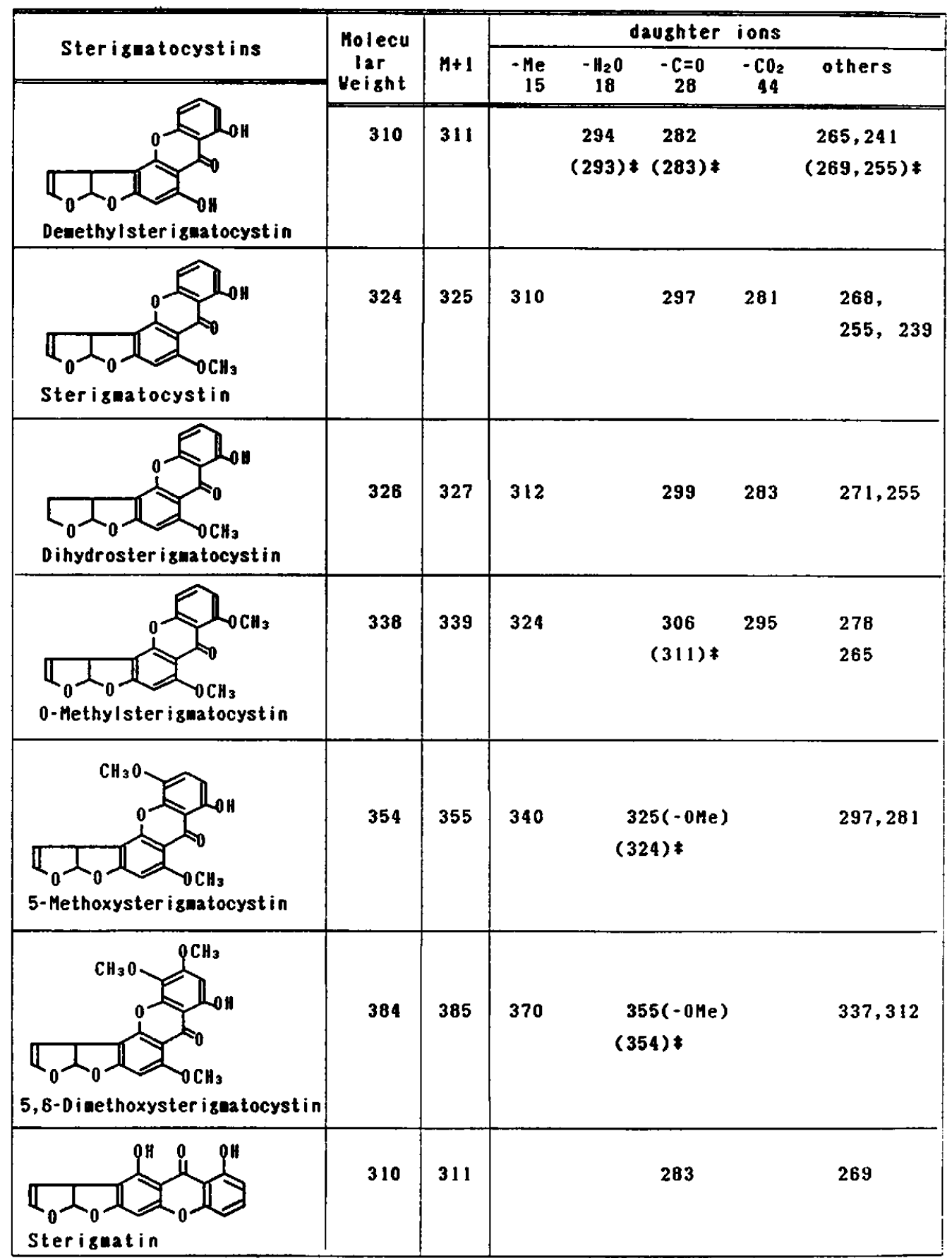


$1 \mu \mathrm{g}$ ) was dissolved in $10 \mu \mathrm{l}$ solvent (dioxane, chloroform or dimethyl sulfoxide). Aliquot of $2 \mu \mathrm{l}$ mycotoxin solution was mixed with matrix (ca $10 \mu \mathrm{l}$ ). The mixture was introduced into the first mass spectrometer which positively ionized the sample with FAB. The sample was irradiated with Xenon gun at $10^{-6}$ torr for ionization in an electric field with $3 \mathrm{kV}$ acceleration. The molecular ion $(M+1)$ of each mycotoxin was selected from the first mass system. It was simultaneously collided with $\mathrm{He}$ gas to produce daughter ions which were subsequently analyzed by the second mass system. The data of each measurement were averaged by accumulation about 10 times.

\section{Results and Discussion}

In ordinary FAB mass analysis, mycotoxins show the molecular ions at $m / z=M+1$ in appreciable abundance. The molecular ion peaks are sufficiently stable for longer than 10 min

Table 3. FAB-MS/MS of versicolorin and its analogs

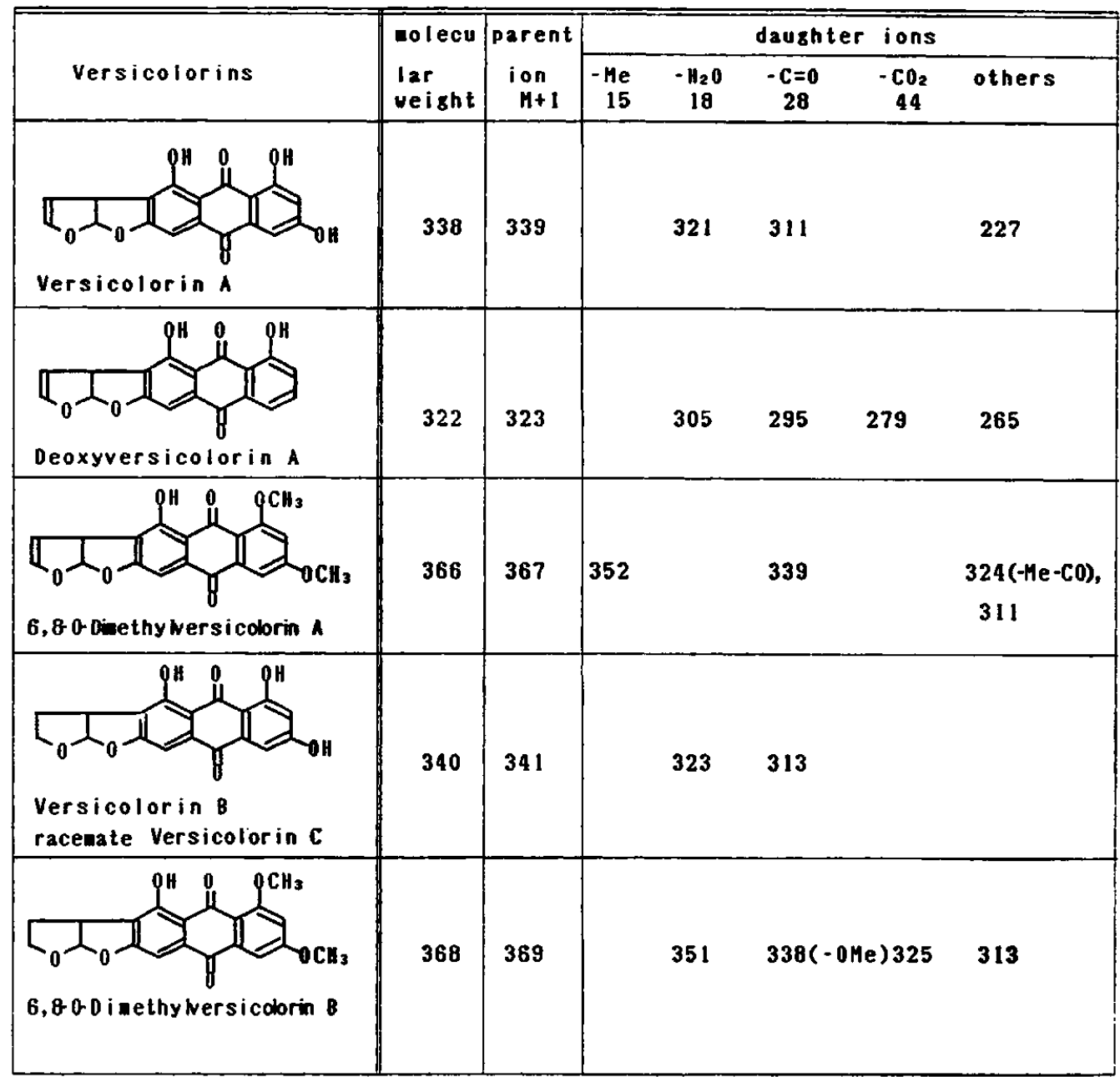


Table 4. FAB-MS/MS of averufin and its analogs

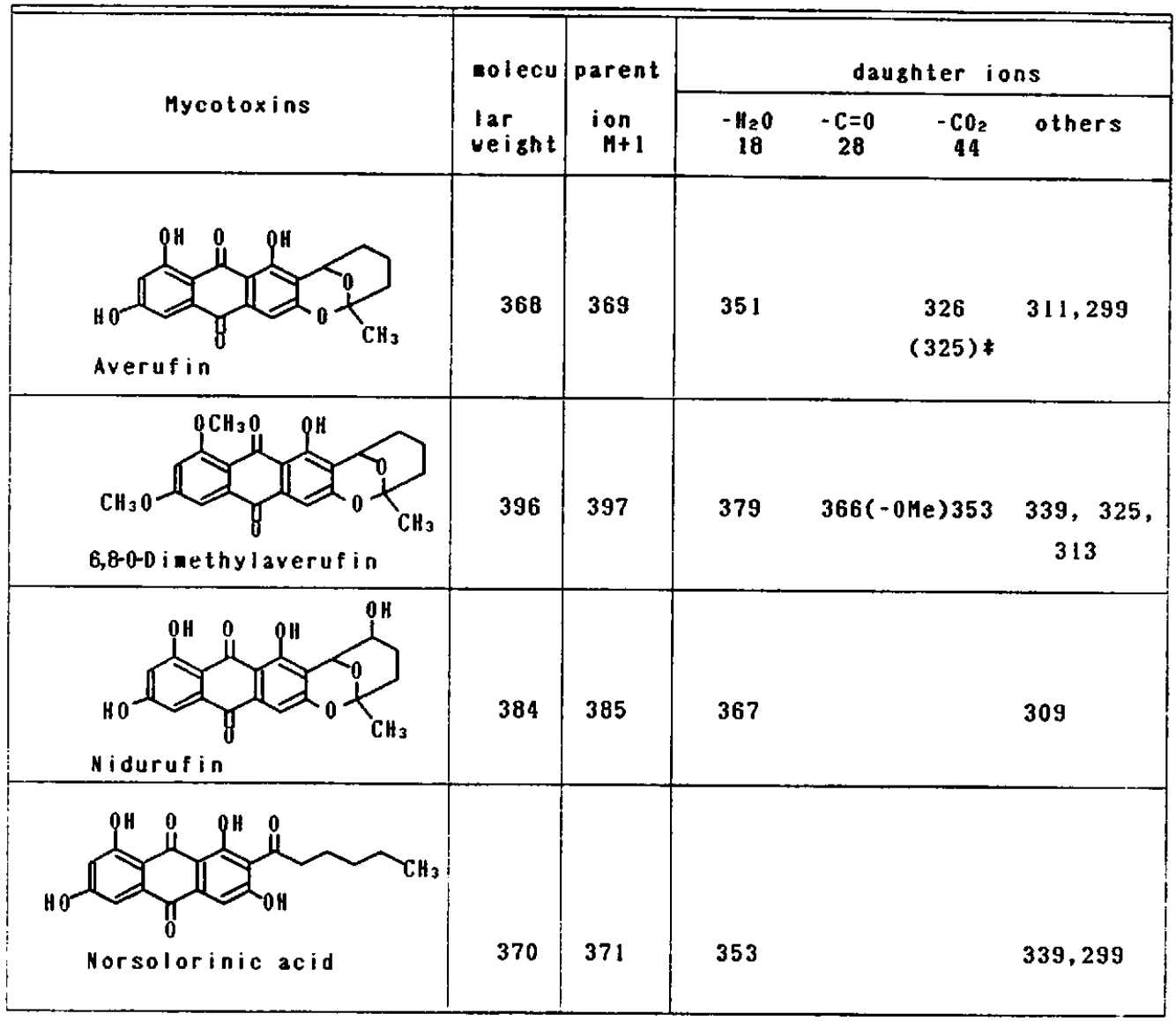

with very little fragmentation; thus, giving only limited information. The application of FAB-MS/MS to analyze mycotoxins is necessary to obtain wider information. The molecular ion $(M+1)$ of each mycotoxin was selected from the first mass system and it was collided with He gas to produce daughter ions which were simultaneously analyzed by the second mass system. Structures of mycotoxins were analyzed and all of the daughter ions are shown in Tables $1,2,3$ and 4 . The main fragmentation behavior of aflatoxins $B_{1}, B_{2}, G_{1}$ and $G_{2}$ gave $\mathrm{M}+1-28(-\mathrm{C}=\mathrm{O})$ and $\mathrm{M}+1-44\left(-\mathrm{CO}_{2}\right)$ pattern. Aflatoxins $\mathrm{B}_{1}$ and $\mathrm{B}_{2}$ showed the same fragment ion at $M+1-15(-M e)$. Aflatoxins $G_{1}$ and $G_{2}$ also possessed the methoxy group of the same position with that of aflatoxins $B_{1}$ and $B_{2}$, but both of them $\left(G_{1}\right.$ and $\left.G_{2}\right)$ showed the fragment ion at $\mathrm{M}+1-18\left(-\mathrm{H}_{2} \mathrm{O}\right)$ instead of $\mathrm{M}+1-15$ as shown in Table 1 . Hence, the correspoding fragments in the mass spectrum of aflatoxin $B$ group and aflatoxin $G$ group follows a different pathway although the structures are closely related with each other. The fragmentation pattern of demethylation and decarbonylation was also found is strigmatocystin and its derivatives as shown in Table 2. In the versicolorin group, the main daughter ions generated by dehydration and decarbonylation were mostly found as shown in Table 3 . 

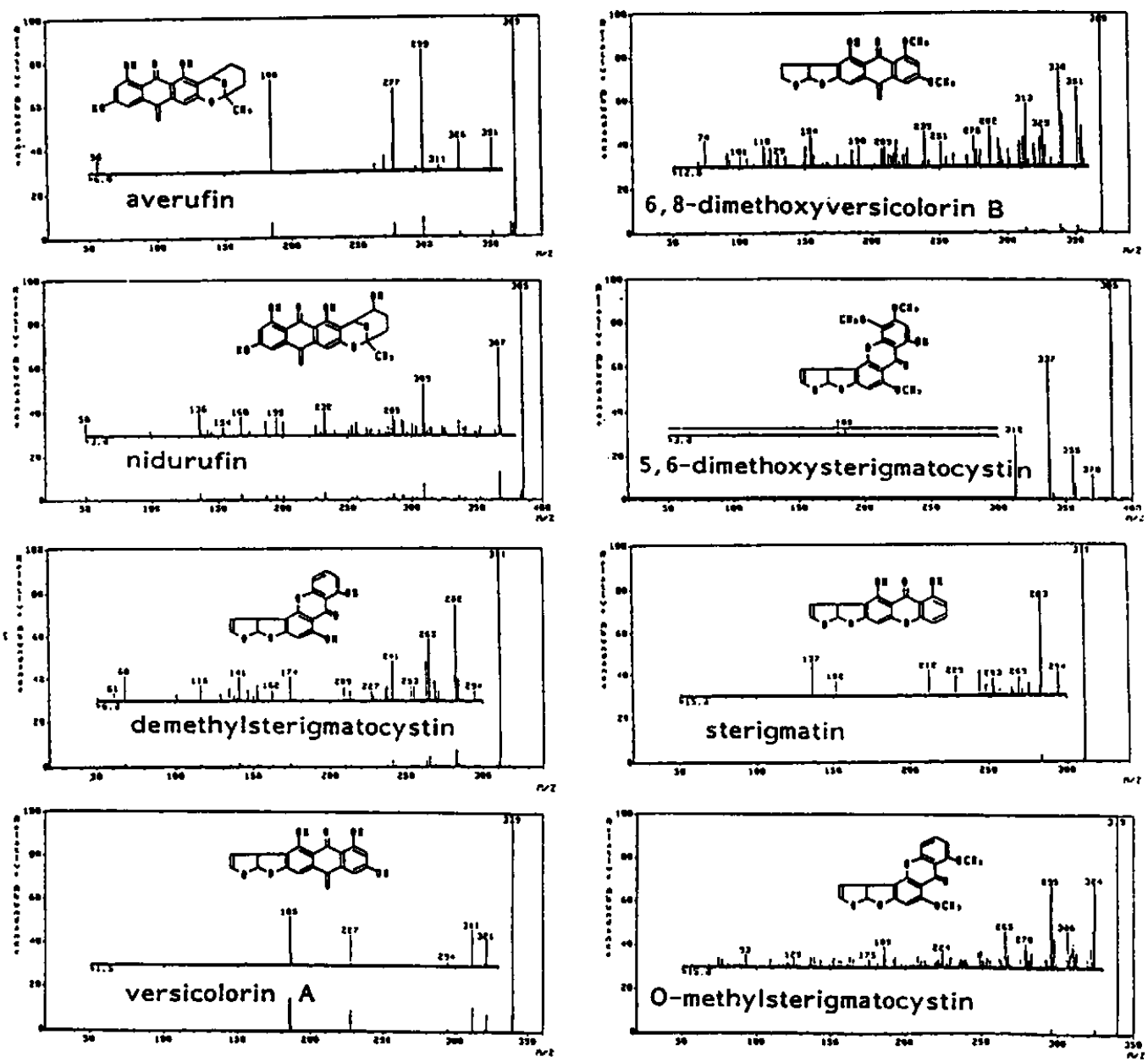

Fig. 1. Tandem FAB mass spectra of 4 pairs of mycotoxins having the same molecular weights.

Averufin, nidurufin and norsolorinic acid were easily dehydrated during fragmentation as shown in Table 4.

The MS/MS analysis of mycotoxins is worthy of the identification and confirmation of the structures from a mixture. A particular mass ion can be selected from the molecular ion mixture formed by the first mass system and rendered fragmentation in the second mass system. The fragmentation spectrum is interpreted with that of an authentic to confirm the presence of such mycotoxin. When the normal mass spectrum dose not supply all the necessary structural information, FAB-MS/MS was especially designed in determining the structures with the same molecular weight. We found that the fragmentation spectrum of averufin was clearly distinguishable from 6,8-O-dimethylversicolorin $B$. In addition nidurufin and 5,6. dimethoxysterigmatocystin; demethylsterigmatocystin and sterigmatin; versicolorin $A$ and $O$ methylsterigmatocystin also provided unambiguous determination as shown in Fig. 1.

The FAB-MS/MS was demonstrated to be a very effective technique for unambiguous 
analyses of mycotoxins even in the same molecular weight ${ }^{10)}$.

\section{Acknowledgements}

The authors are indebted to Mr. Yamamoto, K., Mr. Tsubouchi, H. of Nagoya City Health Research Institute and Prof. Hamasaki, T., for providing the samples, and to Mr. Kitamura, S. for his technical help in mass analysis.

\section{References}

1) Hamasaki, T., Hatsuda, Y. : "Mycotoxins in Human and Animal Health," (Eds. Rodricks, J.V., Hesseltine, C.W., Mehlman, M.A.), p. 597-607 (1977), Pathotox Publishers, Illinois, U.S.A.

2) Aucamp, P. J., Holzapfel, C. W.: J. S. Afr. Chem. Inst., 23, 40 (1970).

3) Pestka, J. J., Gaur, R. K., Chu, F.S.: Appl. Environ. Microbiol., 40, 1027 (1977).

4) Haugen, A., Groopman, J.D., Hsu, I. C., Goodrich, G. R., Wogan, G. N., Harris, C. C.: Proc. Natl. Acad. Sci., U.S.A., 78, 4127 (1981).

5) Pestka, J. J., Li, Y., Harder, W. O., Chu, F.S.: J. Am. Offic. Anal. Chem., 64, 294 (1981).

6) Ueno, I.: Proc. Jpn. Assoc. Mycotoxicol., 21, 24 (1985).

7) Sphon, J. A., Dreifuss, P. A., Schulten, H. R.: J. Am. Offic. Anal. Chem., 60, 73 (1976).

8) Haddon, W. F., Wiley, M., Waiss, Jr. A.C.: Anal. Chem., 43, 268 (1971).

9) Brumley, W.C., Neshelm, S., Trucksess, M. W., Trucksess, E. W., Dreifuss, P. A., Roach, J. A. G., Andrzejewski, D., Eppley, R.M., Pohland, A. E., Thorpe, C. W., Sphon, J. A.: Anal. Chem., 53, 2003 (1981).

10) Uyakul, D., Isobe, M., Goto, T.: J. Am. Offic. Anal. Chem., 72, 491 (1989). 